\title{
Efficient Isolation of High-quality Total RNA from Strawberry
}

\author{
Misaki Ishibashi \\ Department of Plant Resource Science, Graduate School of Agricultural \\ Science, Kobe University, Rokko, Kobe 657-8501, Japan
}

Takeshi Nabe

Department of Immunopharmacology, Faculty of Pharmaceutical Sciences, Setsunan University, 45-1, Nagao-Togecho, Hirakata, Osaka 573-0101, Japan

Yoko Nitta
Department of Nutritional Science, Faculty of Health and Welfare Science,
Okayama Prefectural University, 111 Kuboki, Soja, Okayama 719-1197,
Japan

Yuichi Uno'

Department of Plant Resource Science, Graduate School of Agricultural Science, Kobe University, Rokko, Kobe 657-8501, Japan

Additional index words. high-throughput, next-generation sequencing, real-time PCR, RNA extraction, strawberry organ

\begin{abstract}
Sufficient yields of high-quality RNA are needed for next-generation sequencing and high-throughput real-time polymerase chain reaction analyses. In the case of strawberry (Fragaria $\times$ ananassa) fruits, successful RNA isolation requires removal of abundant inhibitory substances (polysaccharides and polyphenols) that greatly reduce quality and yield. In this study, we applied various combinations of RNA isolation protocols directed at reproductive organs. The best manual isolation method involved nonionic polymer and modified acid guanidinium thiocyanate-phenol-chloroform treatments followed by phenol/chloroform/isoamyl alcohol extraction. Compared with other methods, this approach gave significantly higher yields $[84.0 \mu \mathrm{g} / \mathrm{g}$ fresh weight $(\mathrm{FW})]$ of RNA of greater purity $(\mathbf{A} 260 / \mathrm{A280}=1.99 ; \mathrm{A260} / 230=1.51)$. Better-quality RNA (A260/ $230=2.11)$ was obtained using an automated method, but the yield was lower $(18.1 \mu \mathrm{g} / \mathrm{g}$ FW) than that obtained manually. This automated method consisted of pretreatment with nonionic polymer followed by a silica-based system extraction. Although RNA of sufficient quality [RNA Integrity Number (RIN) $\geq 6.5$ and $28 S / 18 S \geq 1.0$ ] for RNA sequencing was obtained from receptacles using both automated and manual methods, the manual method yielded high-quality RNA from achenes and anthers. The automatic method features 6-fold faster high-throughput capacity, whereas the manual method has wider applicability to different tissues.
\end{abstract}

Strawberry is a popular and important crop worldwide, and contains various food compositions like secondary metabolites (Severo et al., 2015). Therefore, it has been selected as a research material for genome

Received for publication 24 Oct. 2018. Accepted for publication 11 Dec. 2018.

We thank Drs. Takeshi Kurokura (Utsunomiya University), Yasuo Suzuki (Meijo University), Miho Iduhara (Biostir, Inc.), Takashi Kaneda (Promega), and Michio Kanechi (Kobe University) for helpful advice about RNA isolation. We also thank Hiroki Yoshikawa and Shunji Ohkochi (Kobe University) for their technical assistance. This work was supported by the Hyogo Alliance of Universities and Colleges for Innovation, Japan, the Japan Society for the Promotion of Science KAKENHI (grant numbers JP24658030 and JP18J10814), and the Sasakawa Scientific Research Grant from the Japan Science Society (grant number 29-429).

${ }^{1}$ Corresponding author. E-mail: yuno@kobe-u.ac. jp.
BE; Manning, 1991), proprietary methods of various extraction kits (Bianchi et al., 2011), and the use of alkaline buffer and phenolchloroform-isoamyl alcohol (Christou et al., 2014). In addition, Mazzara and James (2000) have developed a protocol for extraction of RNA from strawberry leaf petioles. However, the protocol has not been optimized for RNA quality and yield with fruits and anthers. Although these methods are compatible with subsequent reverse-transcription and/or realtime polymerase chain reaction (PCR) applications, their usefulness when followed by NGS like RNA-seq has not been reported. In cases in which RNA-seq has been applied to various strawberry organs (Hollender et al., 2014; Kang et al., 2013; Sánchez-Sevilla et al., 2014, 2017), they use spin column with silica membrane, or differential precipitation with 2$\mathrm{BE}$; however, extraction protocols have not been optimized for RNA quality and yield. An additional development that needs to be considered is the recent introduction of automated instrumentation that eliminates repetitive and time-consuming manipulations. It is important to evaluate combinations of methods from different companies for developing the best protocol by a disinterested viewpoint. The study described here is the first-reported evaluation of RNA isolation protocols from different strawberry organs for use in NGS and high-throughput analyses.

\section{Materials and Methods}

Materials. Receptacle, achene, and anther organs of strawberry ( $F$. ×ananassa, cultivar 'Akihime') were used. Ripe fruits were immediately frozen in liquid nitrogen and achenes were separated from receptacles by using a scalpel. Anthers were removed from open flowers and frozen in liquid nitrogen. The hard frozen strawberry organs wrapped in aluminum foil were roughly crushed into small pieces by a rigid plastic hammer. All pieces were ground with a mortar and pestle (methods A and D in Table 1) or pulverized with a multi-beads shocker (MBS: Yasui Kikai, Osaka, Japan). When using the MBS (methods $\mathrm{B}, \mathrm{C}, \mathrm{E}$, and $\mathrm{F}$ in Table 1 ), an $\approx 3-\mathrm{mL}$ aliquot of pieces was put into a $50-\mathrm{mL}$ volume tube with a metal cone and were shaken vigorously at 2000 $\mathrm{rpm}$ for $10 \mathrm{~s}$ twice. This process was repeated until all aliquot powders were gathered in a storage tube for every fruit. In all steps, the samples and instruments were kept at low temperature by frequent immersing in a liquid nitrogen. The powdered samples were stored at $-80{ }^{\circ} \mathrm{C}$ until use.

Manual RNA extraction. To extract RNA using Fruit-mate for RNA Purification (Takara Bio, Shiga, Japan), $700 \mu \mathrm{L}$ Fruitmate solution (Takara Bio) was added to 50 to $100 \mathrm{mg}$ powdered sample in all methods except $\mathrm{B}$. The mixture was vortexed and then centrifuged at $13,000 g_{n}$ for $5 \mathrm{~min}$ at $4{ }^{\circ} \mathrm{C}$. An equal volume of Sepasol RNA Super G (Nacalai Tesque, Kyoto, Japan) was added to the supernatant, and the RNA was extracted according to the kit instructions. After incubating the RNA with DNase I (Takara during isolation of RNA from strawberry, including removal by 2-butoxyethanol (2- 
Bio) at $37{ }^{\circ} \mathrm{C}$ for $30 \mathrm{~min}$, the DNase was inactivated using a heat treatment in method A, or by adding Tris-buffered phenol $(\mathrm{pH}=$ 8.0)-chloroform-isoamyl alcohol [25:24:1 $(\mathrm{v} / \mathrm{v} / \mathrm{v})]$ in other methods $(\mathrm{B}, \mathrm{C}, \mathrm{D}$, and $\mathrm{E})$ according to the DNase I instruction manual. RNA was then precipitated with ethanol and resuspended in $50 \mu \mathrm{L}$ RNase-free water. As an additional step in method $\mathrm{E}$, resuspended RNA was added to ethanol and RLT buffer and then purified using an RNeasy Plant Mini kit (Qiagen, Hilden, Germany) according to the instructions in the "RNA cleanup" section of the manufacturer's protocol.

Automated RNA extraction. A Maxwell 16 Automated Purification system (Promega, Madison, WI) was used for automated RNA extraction. As a pretreatment, 50 to $100 \mathrm{mg}$ of powdered sample was mixed with $500 \mu \mathrm{L}$ Fruit-mate. The mixture was then vortexed, followed by centrifugation at $13,000 g_{n}$ for $5 \mathrm{~min}$. To $400 \mu \mathrm{L}$ supernatant, $200 \mu \mathrm{L}$ lysis buffer was added to prepare the sample solution for extraction using a Maxwell 16 LEV Plant RNA kit (Promega). RNA extraction procedures, including a DNase treatment, were conducted according to the Maxwell purification system "RNA-PLANT" protocol.

Determination of RNA yield and quality. Absorbance was determined with a NanoDrop1000 spectrophotometer (Thermo Fisher Scientific, Waltham, MA). Electropherograms, RINs, and $28 \mathrm{~S} / 18 \mathrm{~S}$ ratios of RNA samples were determined using an Agilent 2100 Bioanalyzer (Agilent Technologies, Santa Clara, CA). The resulting RNA samples were stored at $-80{ }^{\circ} \mathrm{C}$.
RNA-seq analysis. Total RNA was isolated from receptacle, achene, and other tissues by different methods: the automated method described previously, and manually using an MBS, Fruit-mate, Sepasol, or an RNeasy kit, followed by phenol-chloroform extraction. Each extracted total RNA was submitted to a custom service (BGI Japan, Kobe, Japan) for complementary DNA (cDNA) library preparation and sequencing reactions. Messenger RNA (mRNA) was isolated by magnetic beads with Oligo (dT) and fragmented. cDNA is synthesized from mRNA fragments followed by adenine attachment. After the adapter ligation, fragments were amplified by PCR to make cDNA library. The cDNA libraries were sequenced on the HiSeq4000 platform (Illumina, San Diego, CA) using paired-end chemistry with 100 -base pair reads. Bioinformatic analysis was carried out using scientifically recognized algorithms according to Ishibashi et al. (2018). Briefly, sequencing reads were filtered by SOAPnuke (Chen et al., 2018). Filtered short-sequence reads were mapped to the $F$. ×ananassa reference database; FAN_r1.1 (Hirakawa et al., 2014) by bowtie/BWA (Langmead et al., 2009). The numbers of expressed genes were estimated using RSEM (Li and Dewey, 2011).

cDNA synthesis and real-time PCR. A ReverTra Ace qPCR RT kit (Toyobo, Osaka, Japan) was used for reverse transcription according to the manufacturer's protocol. The cDNA was synthesized by reversetranscribing $100 \mathrm{ng}$ total RNA using both oligo (dT) and random primers. The cDNA solution was stored at $-20{ }^{\circ} \mathrm{C}$. In real-time
PCR, a LightCycler Nano (Roche Diagnostics, Basel, Switzerland) was used with THUNDERBIRD SYBR quantitative PCR (qPCR) Mix (Toyobo), based on the SYBR Green I dye intercalation method. The PCR assay contained $10 \mu \mathrm{M}$ specific primers, $2 \mu \mathrm{L}$ cDNA solution, and $10 \mu \mathrm{L}$ THUNDERBIRD SYBR qPCR Mix. Primers were designed for the strawberry allergen genes Fra a 1.01 (F: CACACCAAGGGAGATGTCG, R: GGGT GGTCCTTGAGGTATCC) and Fra a 1.02 (F: ACACCAAAGGTGACGTGGA, R: AT TAGGATTGGCCAAGAGGTAG), and for the elongation factor $1 \alpha$ gene $(E F 1 \alpha)$ as the control referred to by Amil-Ruiz et al. (2013) (F: TGGATTTGAGGGTGACAACATGA, R: GTATACATCCTGAAGTGGTAGACG GAGG). The thermal cycling conditions were as follows; $95{ }^{\circ} \mathrm{C}$ for $30 \mathrm{~s}$, three-step amplification with 40 cycles of $95^{\circ} \mathrm{C}$ for $15 \mathrm{~s}$, $60{ }^{\circ} \mathrm{C}$ for $30 \mathrm{~s}$, and $72{ }^{\circ} \mathrm{C}$ for $30 \mathrm{~s}$, pre-melt hold at $95{ }^{\circ} \mathrm{C}$ for $10 \mathrm{~s}$, and melting at 60 to $97{ }^{\circ} \mathrm{C}$ at $0.1{ }^{\circ} \mathrm{C} / \mathrm{s}$. All data were normalized against each $E F 1 \alpha$ transcript level.

Statistical analyses. Statistical analyses were performed using JMP 13 (SAS Institute, Inc., Cary, NC). The data are means \pm standard errors of four biological replicates, and significant differences were determined by Student's $t$ test or TukeyKramer's honestly significant difference test.

Availability of data and materials. The RNA-seq reads supporting the conclusions of this article are available in the DDBJ (http://ddbj.nig.ac.jp/BPSearch/) or NCBI

Table 1. Comparison of quality and yield of RNA extracted from strawberry fruits using various protocols.

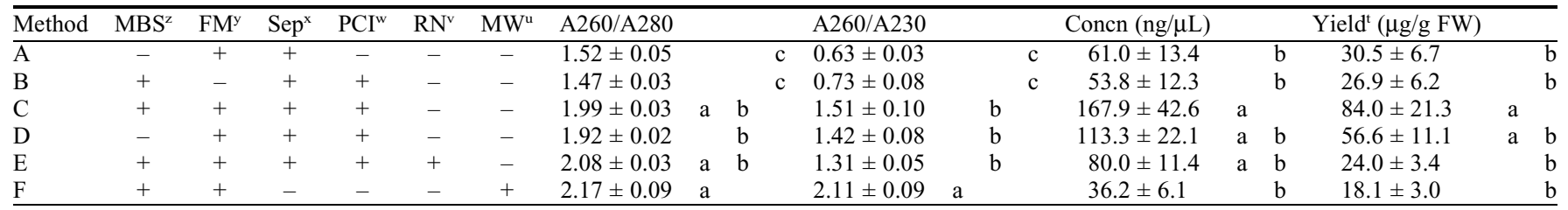

${ }^{\mathrm{z}}$ Multi-Beads Shocker (Yasui Kikai).

${ }^{\mathrm{y}}$ Fruit-mate for RNA Purification (Takara Bio)

${ }^{\mathrm{x}}$ Sepasol RNA Super G (Nacalai Tesque).

${ }^{\text {w}}$ Phenol-chloroform-isoamyl alcohol extraction.

${ }^{\mathrm{v}} \mathrm{RNeasy}$ Plant Mini kit (Qiagen).

uMaxwell 16 Automated Purification system (Promega).

${ }^{t} Y$ ield $[\mu \mathrm{g} / \mathrm{g}$ fresh weight $(\mathrm{FW})]$ were calculated from concentration and total volume of RNA solution, and FW of the original frozen powder; (concentration; $\mathrm{ng} / \mu \mathrm{L}) \times($ volume; $\mu \mathrm{L}) \times 10^{-3} /(\mathrm{FW} ; \mathrm{g})$.

Different letters following values indicate significant differences $(P<0.05$; Tukey-Kramer's honestly significant difference test, $\mathrm{n}=4)$.

Table 2. Quality and yield of RNA obtained from different strawberry organs using manual and automated methods.

\begin{tabular}{|c|c|c|c|c|c|c|c|c|c|}
\hline Organ & $\mathrm{A} 260 / \mathrm{A} 280^{\mathrm{z}}$ & $\mathrm{A} 260 / \mathrm{A} 230^{\mathrm{z}}$ & Concn $(\mathrm{ng} / \mu \mathrm{L})^{\mathrm{z}}$ & Yield $(\mu \mathrm{g} / \mathrm{g} \mathrm{FW})^{2}$ & $\mathrm{RIN}^{\mathrm{y}}$ & $28 \mathrm{~S} / 18 \mathrm{~S}^{\mathrm{y}}$ & Clean reads ${ }^{\mathrm{x}}$ & Genome map rate $(\%)^{\mathrm{x}}$ & Expressed genes \\
\hline Receptacle & 2.06 & 1.60 & 257.2 & 128.6 & 10.0 & 1.6 & $-\mathrm{w}$ & - & - \\
\hline Achene & 2.14 & 2.06 & 1024.9 & 614.9 & 8.1 & 1.8 & 77277796 & 64.70 & 68421 \\
\hline Anther & 2.03 & 1.86 & 443.2 & 265.9 & 8.9 & 1.7 & 83108866 & 63.54 & 58779 \\
\hline Receptacle & 2.23 & 2.11 & 31.9 & 16.0 & 7.4 & 1.6 & 97008546 & 59.72 & 70689 \\
\hline Achene & 2.08 & 2.09 & 94.9 & 94.9 & 2.1 & 0.0 & - & - & - \\
\hline Anther & 2.09 & 2.13 & 107.8 & 107.8 & 3.8 & 0.3 & - & _- & - \\
\hline
\end{tabular}

${ }^{\mathrm{z}}$ Absorbance at 230, 260, and $280 \mathrm{~nm}$ was measured using a Nanodrop1000 spectrophotometer. Absorbance values were used to calculate purity, concentration, and yield.

${ }^{y}$ RNA integrity numbers were determined using an Agilent 2100 Bioanalyzer (see also Fig. 1).

${ }^{\mathrm{x}}$ Number of clean reads, percentage of mapped reads, and number of expressed genes were based on Illumina HiSeq4000 next-generation sequencing. Clean reads were mapped to the $F$. xananassa reference database; FAN_r1.1 (Hirakawa et al., 2014).

${ }^{\mathrm{w}} \mathrm{A}$ dash entry indicates sample was not tested. 
(http://www.ncbi.nlm.nih.gov/bioproject/) with accession ID PRJDB7716.

\section{Results and Discussion}

Establishment of a manual protocol combining various steps for efficient RNA isolation. We investigated a series of manual RNA isolation methods based on different chemical kits. The various combinations, given as method types $\mathrm{A}$ to $\mathrm{E}$, are shown in Table 1.

Before extraction, samples were pulverized using either an MBS or a mortar and pestle. Although RNA purity and yield were not significantly increased by using the MBS grinding method (Table 1, methods C and D), this technique was faster and improved reproducibility by increasing particle size uniformity. Sepasol was used as the first extraction step. Sepasol is a commercial reagent containing thiocyanate compounds based on the AGPC method (Chomczynski and Sacchi, 1987), as well as TRIZOL (Thermo Fisher Scientific) or TRI Reagent (Sigma-Aldrich, St. Louis, MO). Although these reagents are slightly different in components, they can be used compatibly. These thiocyanate compounds denature proteins including RNases, and the addition of phenolchloroform partitions RNA into the aqueous phase and DNA and protein into the phenolchloroform phase. The simplest method, B, resulted in the lowest quality and yield values. In this case, a red color corresponding to incomplete removal of polyphenols was visible after RNA precipitation. Gehrig et al. (2000) noted that polysaccharides can coprecipitate with RNA in low ionic-strength buffers. This problem can be addressed using Fruit-mate, which contains a nonionic polymer that binds polysaccharides and polyphenols. As shown in Table 1, method $\mathrm{C}$ using Fruit-mate was significantly better than method B, according to our RNA evaluation criteria. After treatment with DNase I, the enzyme was inactivated by heating (Table 1, method A) or phenol-chloroform extraction (Table 1, methods B-E). The purity of RNA obtained using method D was significantly better than that obtained using method A, suggesting that phenol-chloroform is efficient not only for inactivation of DNase I but also for elimination of polyphenols. This finding is consistent with a report that phenol binds to phenolic compounds (Rayani and Nayeri, 2015). An RNeasy Plant Mini spin column was used to further purify RNA. This type of column, which contains a silica-gelbased membrane, is based on the Boom method. The Boom method exploits the binding of nucleic acids to silica in the presence of chaotropic salts, such as guanidinium ions (Boom et al., 1990). The RNeasy column was not very effective for purifying strawberry RNA and significantly decreased
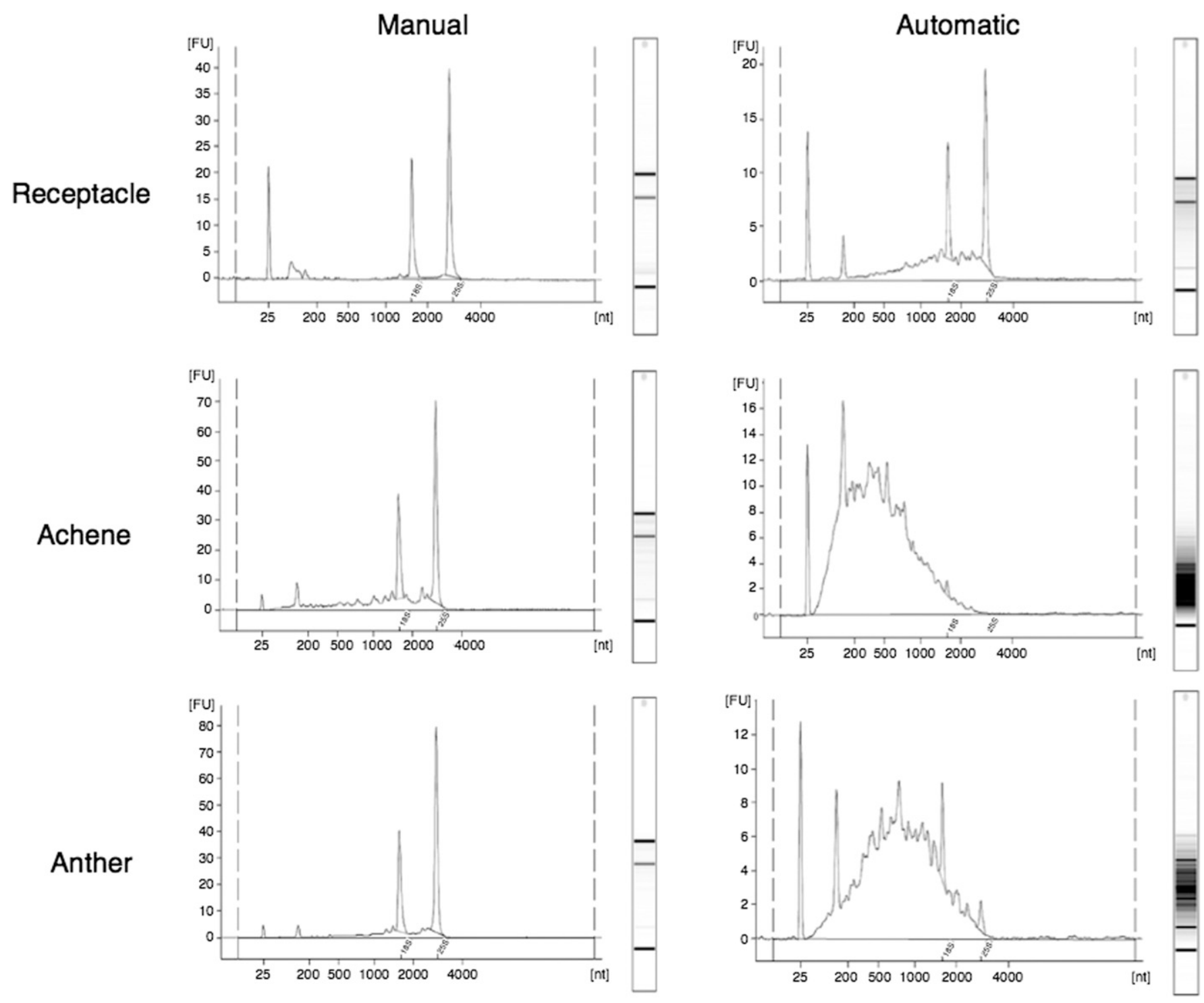

Fig. 1. Electropherograms of RNA isolated from different organs of strawberry. RNA was extracted from receptacles (upper) and achenes (middle) of ripe fruits and anthers (lower) of flowers in full bloom using manual (left) or automated (right) methods. The manual method included Fruit-mate and Sepasol treatments followed by phenol-chloroform-isoamyl alcohol extraction, and the automated method consisted of Fruit-mate pretreatment followed by application of the Promega Maxwell system (see also Table 2). Electropherograms were generated on an Agilent 2100 Bioanalyzer.The x-and y-axes represent nucleotides (nt) and relative fluorescence units (FU), respectively. 
yields (Table 1 , method $\mathrm{E}$ in contrast to method C). We presume that complexes of RNA and impurities, such as polysaccharides, clogged the column or passed through the column before the elution step. According to the instruction manual, normal lysis buffer (Buffer RLT) contains guanidine thiocyanate and coagulates RNA and secondary metabolites depending on plant tissues. Another lysis buffer containing guanidine hydrochloride (Buffer RLC), which is recommended in case of the sample solidification, had no effect on RNA quality and yield (data not shown).

The combination of Fruit-mate, Sepasol, and phenol-chloroform extraction (Table 1, method C) was accordingly the best of tested manual protocols for isolation of RNA from strawberry fruits. This protocol was highly applicable to young leaves in both quality and quantity $(831.4 \mu \mathrm{g} / \mathrm{g} \mathrm{FW}, \mathrm{A} 260 / \mathrm{A} 280=1.89$, $\mathrm{A} 260 / \mathrm{A} 230=1.85)$. Compared with the protocol described by Christou et al. (2014), method $\mathrm{C}$ resulted in higher yields and superior quality of RNA $(23.7 \mu \mathrm{g} / \mathrm{g} \mathrm{FW}$, A260/A280 $=1.78$, and A260/A230 $=1.04$ in the former). The method $\mathrm{C}$ gave almost the same yields and the lower value of A260/ A230 in comparison with the procedure

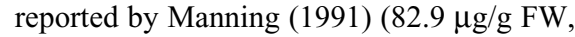
A260/A280 $=$ not determined, and A260/ A230 = 2.07). Because Manning's (1991) protocol has many steps, including overnight precipitation with $\mathrm{LiCl}$, the limited steps for
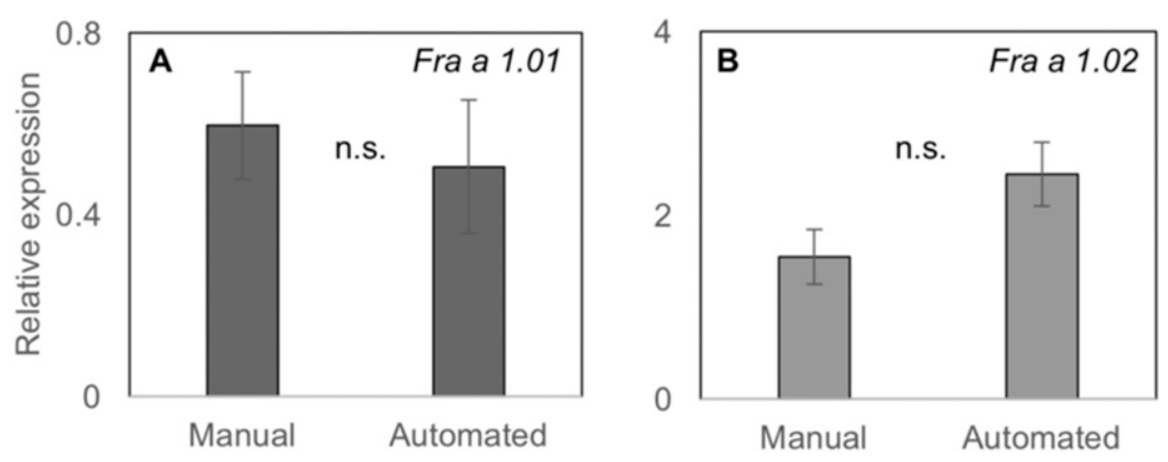

Fig. 2. Analyses of gene transcript levels of Fra a 1 in strawberry by real-time polymerase chain reaction. RNA was extracted from receptacles of ripe fruits using manual or automated methods (see legend to Table 1). Relative transcript levels of Fra a 1.01 (A) and Fra a 1.02 (B) normalized against that of the elongation factor $1 \alpha$ gene $(E F 1 \alpha)$. Significant differences were not detected between RNA isolation methods as indicated by n.s. $(P<0.05$; Student's $t$ test, $\mathrm{n}=4)$. traction from receptacles using either manual or automated methods yielded RNA of sufficient quality for NGS (RIN $\geq 6.5$ and $28 \mathrm{~S}$ / $18 \mathrm{~S} \geq 1.0$; Table 2). When the electropherograms of RNA samples prepared using manual and automated methods were compared, the RNA obtained using the automated method was somewhat degraded, but its quality and quantity were sufficient for library preparation (Fig. 1). In contrast, RNA isolated from achenes and anthers by the automated method was of insufficient quality for NGS (RIN < 3.8 and $28 \mathrm{~S} / 18 \mathrm{~S}<0.3$; Table 2), with many peaks representing impurities and RNA degradation visible on electropherograms (Fig. 1). RNA extracted from achenes and anthers using the manual method had higher RIN and $28 \mathrm{~S} / 18 \mathrm{~S}$ values indicating its suitability for use in NGS. Our results indicate that the selection of the most appropriate RNA isolation method depends on the plant organ used as an RNA source.

Application of RNA isolation methods to downstream assays. To validate the quality of RNA for downstream assays, RNA samples were used in real-time PCR and NGS analyses. Target gene was Fra a 1 , encoding major allergenic protein in $F$. Xananassa because we have already established the evaluation system by real-time PCR (Ishibashi et al., 2018). In both Fra a 1.01 and Fra a 1.02 genes, no statistically significant difference was found in relative transcript levels between RNAs isolated by manual and automated methods (Fig. 2). For both genes, a single peak was observed from each sample, with no amplification of multiple homologs (Fig. 3). These results indicate that the tested manual and automated methods of RNA isolation are equally suitable for detecting Fra a 1 genes in real-time PCR. Accordingly, automated methods are more advantageous for high-throughput expression analyses. For use in high-throughput analyses, 16 samples could be pretreated and processed in $1.5 \mathrm{~h}$ by the automated method, compared with 6 samples manually in $3.5 \mathrm{~h}$. The time required of the automated method is six times faster than that of the manual.

Three RNA samples were submitted to a commercial RNA-seq service. After filtering of raw RNA-seq reads, the resulting clean reads were aligned to the reference genome
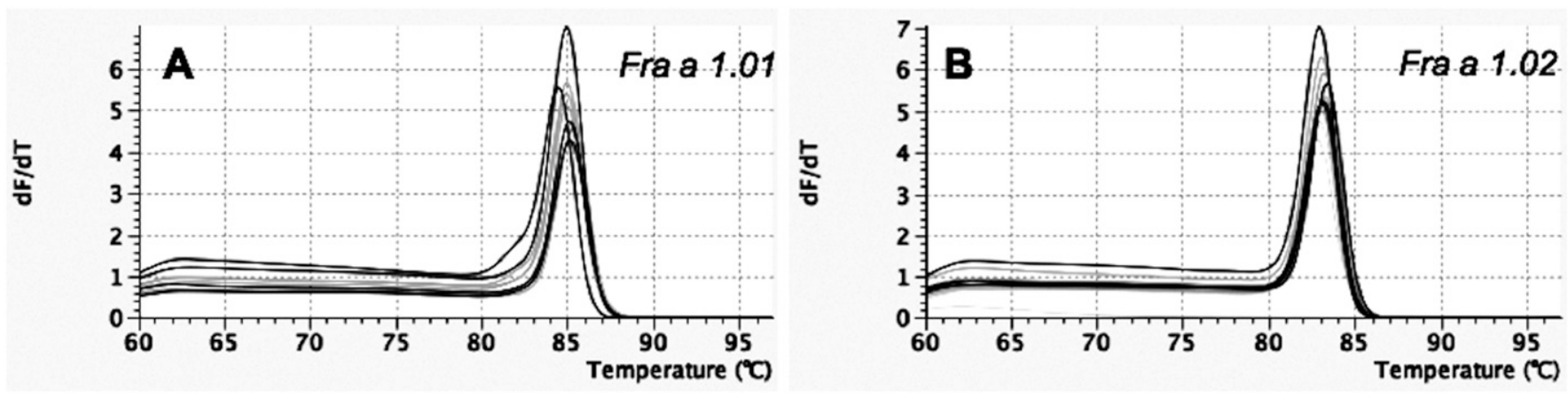

Fig. 3. Melting peak analyses of Fra a 1.01 (A) and Fra a 1.02 (B) conducted after polymerase chain reaction amplifications. RNA was extracted from receptacles of ripe fruits using manual (gray line) or automated (black solid line) methods (see also Fig. 2). 
(F. ×ananassa, FAN_r1.1; Hirakawa et al., 2014). All samples generated more than 77 million clean reads $(>99 \%$ of raw reads), comparable to the 30 million clean reads ( $97 \%$ of raw reads) of a previous study (Sánchez-Sevilla et al., 2014). Genome mapping rates ranged from $60 \%$ to $65 \%$, which was slightly lower than previously reported values of $68 \%$ ( $F$. Xananassa to the $F$. vesca v1.1 reference genome; Sánchez-Sevilla et al., 2014) and $69 \%$ (F. vesca to the $F$. vesca v1.0 reference genome; Hollender et al., 2014). In contrast, the number of expressed genes, which ranged from 58,799 to 70,689 , was higher than the number reported in the two earlier studies $(33,458$ in Sánchez-Sevilla et al., 2014; and 24,161 in Hollender et al., 2014). The output data, which are summarized in Table 2, confirmed that all submitted RNA samples were of sufficient quality and quantity for RNA-seq analyses.

We have optimized the protocol of RNA isolation from strawberry organs for the practical detection of genes. The advantage of the automated method is its highthroughput capacity, whereas the manual method is applicable to a broader array of plant organs. Both methods produced RNA of sufficient quality and yield for RNA-seq and real-time PCR analyses.

\section{Literature Cited}

Amil-Ruiz, F., J. Garrido-Gala, R. Blanco-Portales, K.M. Folta, J. Muñoz-Blanco, and J.L. Caballero. 2013. Identification and validation of reference genes for transcript normalization in strawberry (Fragaria $\times$ ananassa) defense responses. PLoS One 8:e70603.

Bianchi, S., A.D. Vecchio, M.L. Vilariño, and J.L. Romalde. 2011. Evaluation of different RNAextraction kits for sensitive detection of Hepatitis A virus in strawberry samples. Food Microbiol. 28:38-42.

Boom, R., C.J.A. Sol, M.M.M. Salimans, C.L. Jansen, P.M.E. Wertheim van Dillen, and J. van der Noordaa. 1990. Rapid and simple method for purification of nucleic acids. J. Clin. Microbiol. 28:495-503.

Chen, Y., Y. Chen, C. Shi, Z. Huang, Y. Zhang, S. Li, Y. Li, J. Ye, C. Yu, Z. Li, X. Zhang, J. Wang, H. Yang, L. Fang, and Q. Chen. 2018. SOAPnuke: A MapReduce acceleration-supported software for integrated quality control and preprocessing of high-throughput sequencing data. Gigascience 7:1-6.

Chomczynski, P. and N. Sacchi. 1987. Single-step method of RNA isolation by acid guanidinium thiocyanate-phenol-chloroform extraction. Anal. Biochem. 162:156-159.

Christou, A., E.C. Georgiadou, P. Filippou, G.A. Manganaris, and V. Fotopoulos. 2014. Establishment of a rapid, inexpensive protocol for extraction of high quality RNA from small amounts of strawberry plant tissues and other recalcitrant fruit crops. Gene 537:169-173.

Davis, A.R., A. Levi, S. Kim, S.R. King, and A. Hernandez. 2006. RNA extraction method from fruit tissue high in water and sugar. HortScience 41:1292-1294.

Gehrig, H.H., K. Winter, J. Cushman, A. Borland, and T. Taybi. 2000. An improved RNA isolation method for succulent plant species rich in polyphenols and polysaccharides. Plant Mol. Biol. Rpt. 18:369-376.

Giampieri, F., J.M. Alvarez-Suarez, and M. Battino. 2014. Strawberry and human health: Effects beyond antioxidant activity. J. Agr. Food Chem. 62:3867-3876.

Hirakawa, H., K. Shirasawa, S. Kosugi, K. Tashiro, S. Nakayama, M. Yamada, M. Kohara, A. Watanabe, Y. Kishida, T. Fujishiro, H. Tsuruoka, C. Minami, S. Sasamoto, M. Kato, K. Nanri, A Komaki, T. Yanagi, Q. Guoxin, F. Maeda, M. Ishikawa, S. Kuhara, S. Sato, S. Tabata, and S.N. Isobe. 2014. Dissection of the octoploid strawberry genome by deep sequencing of the genomes of Fragaria species. DNA Res. 21:169-181.

Hollender, C.A., C. Kang, O. Darwish, A. Geretz, B.F. Matthews, J. Slovin, N. Alkharouf, and Z. Liu. 2014. Floral transcriptomes in woodland strawberry uncover developing receptacle and anther gene networks. Plant Physiol. 165:10621075.

Ishibashi, M., T. Nabe, Y. Nitta, H. Tsuruta, M. Iduhara, and Y. Uno. 2018. Analysis of major paralogs encoding the Fra a 1 allergen based on their organ-specificity in Fragaria $\times$ ananassa. Plant Cell Rep. 37:411-424.

Kang, C., O. Darwish, A. Geretz, R. Shahan, N. Alkharouf, and Z. Liu. 2013. Genome-scale transcriptomic insights into early-stage fruit development in woodland strawberry Fragaria vesca. Plant Cell 25:1960-1978.

Langmead, B., C. Trapnell, M. Pop, and S.L. Salzberg. 2009. Ultrafast and memory-efficient alignment of short DNA sequences to the human genome. Genome Biol. 10:R25.

Li, B. and C.N. Dewey. 2011. RSEM: Accurate transcript quantification from RNA-Seq data with or without a reference genome. BMC Bioinformatics 12:323.

Manning, K. 1991. Isolation of nucleic acids from plants by differential solvent precipitation. Anal. Biochem. 195:45-50.

Mazzara, M. and D.J. James. 2000. The influence of photoperiodic growth condition on isolation of RNA from strawberry (Fragaria $\times$ ananassa Duch.) tissue. Mol. Biotechnol. 15:237-241.

Nuyts, S., L. Van Mellaert, P. Lambin, and J. Anné. 2001. Efficient isolation of total RNA from Clostridium without DNA contamination. J. Microbiol. Methods 44:235-238.

Rayani, A. and F.D. Nayeri. 2015. An improved method for extraction of high-quality total RNA from oil seeds. Biotechnol. Lett. 37:927-933.

Sánchez-Sevilla, J.F., E. Cruz-Rus, V. Valpuesta, M.A. Botella, and I. Amaya. 2014. Deciphering gamma-decalactone biosynthesis in strawberry fruit using a combination of genetic mapping, RNA-Seq and eQTL analyses. BMC Genomics 15:218-232.

Sánchez-Sevilla, J.F., J.G. Vallarino, S. Osorio, A Bombarely, D. Posé, C. Merchante, M.A. Botella, I. Amaya, and V. Valpuesta. 2017. Gene expression atlas of fruit ripening and transcriptome assembly from RNA-seq data in octoploid strawberry (Fragaria $\times$ ananassa). Sci. Rep. 7:13737.

Schroeder, A., O. Mueller, S. Stocker, R. Salowsky, M. Leiber, M. Gassmann, S. Lightfoot, W. Menzel, M. Granzow, and T. Ragg. 2006. The RIN: An RNA integrity number for assigning integrity values to RNA measurements. BMC Mol. Biol. 7:3.

Severo, J., I.R. de Oliveira, A. Tiecher, F.C. Chaves, and C.V. Rombaldi. 2015. Postharvest UV-C treatment increases bioactive, ester volatile compounds and a putative allergenic protein in strawberry. Lebensm. Wiss. Technol. 64:685-692.

Shulaev, V., D.J. Sargent, R.N. Crowhurst, T.C. Mockler, O. Folkerts, A.L. Delcher, P. Jaiswal, K. Mockaitis, A. Liston, S.P. Mane, P. Burns, T.M. Davis, J.P. Slovin, N. Bassil, R.P. Hellens, C. Evans, T. Harkins, C. Kodira, B. Desany, O.R. Crasta, R.V. Jensen, A.C. Allan, T.P. Michael, J.C. Setubal, J. Celton, D.J.G. Rees, K.P. Williams, S.H. Holt, J. Jairo, R. Rojas, M. Chatterjee, B. Liu, H. Silva, L. Meisel, A. Adato, S.A. Filichkin, M. Troggio, R. Viola, T. Ashman, H. Wang, P. Dharmawardhana, J. Elser, R. Raja, H.D. Priest, D.W. Bryant Jr., S.E. Fox, S.A. Givan, L.J. Wilhelm, S. Naithani, A. Christoffels, D.Y. Salama, J. Carter, E.L. Girona, A. Zdepski, W. Wang, R.A. Kerstetter, W. Schwab, S.S. Korban, J. Davik, A. Monfor, B. Denoyes-Rothan, P. Arus, R. Mittler, B. Flinn, A. Aharoni, J.L. Bennetzen, S.L. Salzberg, A.W. Dickerman, R. Velasco, M. Borodovsky, R.E. Veilleux, and K.M. Folta. 2011. The genome of woodland strawberry (Fragaria vesca). Nat. Genet. 43:109-118.

Wang, G., G. Wang, X. Zhang, F. Wang, and R. Song. 2012. Isolation of high quality RNA from cereal seeds containing high levels of starch. Phytochem. Anal. 23:159-163. 